\title{
EFFECT OF SYMBIOTIC ICE CREAM SUPPLEMENTATION ON IMMUNE RESPONSE, GENERAL HEALTH, SLEEPINESS AND MOOD OF MILITARY IN FIELD TRAINING.
}

\author{
Isabel de A. Vieira*, Maria C. Pelatieri, Darlila A. Gallina, Diogo T. Cunha, Adriane E. A. Moraes.
}

\begin{abstract}
The aim of this study was to evaluate the effect of symbiotic ice cream supplementation on immune response, mood and health parameters of military volutaries from the "Escola Preparatória de Cadetes" (Army Preparatory School) from Campinas during field training. This evaluation was done through the collection of saliva for the evaluation of $\lg A$ and through the application of questionnaires in three phases: after the washout period $(t=0)$, after supplementation in the period prior to field training $(t=1)$ and after field training $(t=2)$. It was possible to observe that after training there was a significant decrease in salivary $\operatorname{lgA}$ for both symbiotic and placebo group. In addition, the symbiotic group had significantly increased tranquility and reduced tension after training while the placebo group did not show changes in both states after training. These results demonstrate the importance of investigating the effects of probiotics associated with prebiotics on gut - brain axis.
\end{abstract}

\section{Key words:}

Probiotic, prebiotic, supplementation.

\section{Introduction}

Simulation of acute survival - a common pratice among military - may impair the immune system and can result in some heath problems, and can also negatively influence the mood and well-being of these individuals (EDWARDS et al., 2013; LIEBERMAN et al., 2005). Probiotics have been suggested as health promoters by reducing the symptoms above mentioned (FLOCH et al., 2008). The aim of this project was to observe the effects of symbiotic ice cream consumption in health-related events of military voluntaires after the field training period.

\section{Results and Discussion}

This was a randomized double-blind study, with 65 students (male and female) divided into two groups (symbiotic and placebo) wich received $60 \mathrm{~g}$ of ice cream during 30 days produced by our group at Instituto de Tecnologia de Alimentos (Food Technology Institute) from Campinas. Each consumption portion of the symbiotic ice cream had $2,5 \mathrm{~g}$ of prebiotic (inulin), $1.2 \times 10^{10}$ and $1.2 \times 10^{11} \mathrm{CFU}$ of the probiotics $L$. acidophilus LA5 and $B$. animalis BB12, respectively. The placebo ice cream had no pre and probiotic addition, but was incorporated of $0,1 \%$ of CMC (carboxymetlyl celulose) to mimic the texture of the symbiotic product. The present study was approved by the Ethics Committee (n 90850718.8.0000.5404). The immune system status was evaluated through salivary $\lg A$ values, and the state of mood and well-being, general health and sleepiness were evaluated through questionnaires application.

Regarding salivary IgA (values expressed at Table 1) there was a significant reduction for both groups, being placebo $p=<0.01$ and supplemented $p=<0.001$. However the consumption of symbiotic ice cream did not preserve salivary $\lg A$ values after the field training period.

Table 1. Salivary IgA analysis

\begin{tabular}{ccccc}
\hline Group & & Mean & Std. D. & p \\
\hline \multirow{2}{*}{ Placebo } & pre & 24,87 & 34,60 & \multirow{2}{*}{00,01} \\
& post & 9,90 & 8,76 & \\
\hline \multirow{2}{*}{ Symbiotic } & pre & 23,53 & 17,17 & \multirow{2}{*}{$<0,001$} \\
& post & 10,13 & 6,19 & \\
\hline
\end{tabular}

$p<0.05$ indicates statistical difference. Pre and post - before and after field training.
Regarding the state of humor and well-being, the results are expressed at Table 2. It was observed that before and after the training both groups had an increase in the happiness state after the field training period, and the placebo group maintained the state of sleepiness.

While the placebo group did not have a significant change in the state of tranquility and tension after the training period, the symbiotic group has demonstrated elevation of the state of tranquility and reduction of the state of tension, and both diferences were statisticaly significant.

This indicates that probiotics associated with prebiotics have the potential to modulate mood and well-being through their action on the gut-brain axis.

Table 2. Mood and well-being analysis

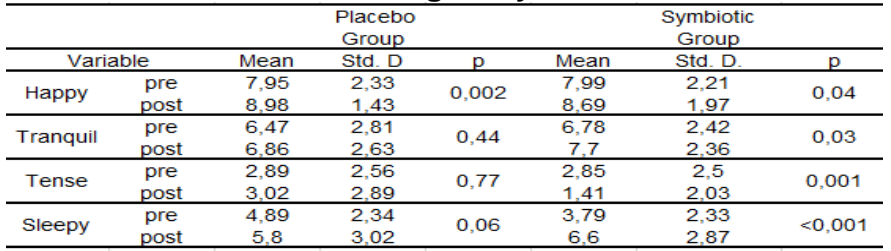

$\mathrm{p}<0.05$ indicates statistical difference Pre and post - before and after field training.

\section{Conclusions}

Although symbiotic ice cream was not effective in maintaining salivary $\lg \mathrm{A}$ levels after field training period, the supplementation was effective influencing the gutbrain axis, with some positive consequences on mood and well-being states, such as the reduction of tension and increased tranquility. Thus, other effects related to the gut-brain axis need further studies, expanding the target public for supplementation.

\section{Acknowledgement}

\section{CNPq and Escola Preparatória de Cadetes (EsPCEx).}

ANNALISE L C.; EDWARDS, A. M.; CROWE, M.; QUIRK, F. Physiological, Biochemical, and Psychological Responses to Environmental Survival Training in the Royal Australian Air Force, Military Medicine, Volume 178 Issue 7, 1 July 2013, Pages e829-e835.

FLOCH, M. H. et al. Recommendations for probiotic use-2008. J Clin Gastroenterol 2008; 42 (Suppl 2): S104-8.

LIEBERMAN, H. R. et al.: Severe decrements in cognition function and mood induced by sleep loss, heat, dehydration, and undernutrition during simulated combat. Biol Psychiatry 2005; 57: 422-9. 